\title{
Pull Breech out versus Push Impacted Head up in Emergency Cesarean Section: A Comparative Study
}

\author{
Hend S. Saleh, Gamal A. Kassem, Mohamed El Said Mohamed, Moustafa A. Ibrahiem, \\ Manal M. El Behery* \\ Faculty of Medicine, Zagazig University, Zagazig, Egypt \\ Email:
}

Received 19 February 2014; revised 12 March 2014; accepted 20 March 2014

Copyright (C) 2014 by authors and Scientific Research Publishing Inc.

This work is licensed under the Creative Commons Attribution International License (CC BY).

http://creativecommons.org/licenses/by/4.0/

c) (i) Open Access

\begin{abstract}
Objective: To compare maternal and fetal outcome associated with two methods Reverse breech extraction versus Head pushing to deliver the impacted fetal head in advanced labor requiring emergency Cesarean section. Method: A prospective comparative study was conducted on 80 pregnant women at term with cephalic presentation in advanced labour, requiring emergency Cesarean Section. Reverse breech extraction technique (pull method) was used in 40 cases (group I) and pushing the head up through the vagina ("push" method) was tried in (group II) 40 cases. The maternal outcome was assessed by extension of the uterine Incision, bladder injury, intra and postoperative blood transfusion, Postpartum hemorrhage, wound infection and duration of hospital stay. Fetal outcome was Apgar score and admission to neonatal intensive care unit. Results: Extension of the uterine incision was significantly lower in women undergoing reverse breech extraction compared to cephalic delivery $(20 \%$ versus $50 \% ; p=0.001)$. The mean operative time (pull group) was lower than that in the (push group) $59.7 \pm 4.2$, versus $75.2 \pm 6.1 p=0.001$ and blood loss was significantly lower in the (pull group) than that in the (push group) $878 \pm 67 \mathrm{ml}$, versus $1321 \pm 57 \mathrm{ml}, p=0.001$. No significant difference between groups regarding maternal and neonatal outcome. Conclusion: Reverse breech extraction (pull) is safer than pushing head up through vagina (push) for delivery of a deeply impacted fetal head in advanced labour sensitizing emergency Cesarean Section and is associated with the least maternal complications.
\end{abstract}

\section{Keywords}

Deeply Engaged Head; Obstructed Labor; Cesarean Section; Reverse Breech Extraction; Head Push Method

\footnotetext{
${ }^{*}$ Corresponding author.
}

How to cite this paper: Saleh, H.S., et al. (2014) Pull Breech out versus Push Impacted Head up in Emergency Cesarean Section: A Comparative Study. Open Journal of Obstetrics and Gynecology, 4, 260-265. 


\section{Introduction}

Emergency Caesarean section is performed as an obstetric emergency, where intrapartum complications suddenly raised, and swift action is required to prevent the demises of mother, fetus or both [1]-[3]. Obstructed labor occurs when there is no progress in labor in spite of strong uterine contraction as shown by failure of cervix to dilate or failure of presenting part to descend through birth canal [4].

Although rare in developed countries, obstructed labor is still a common obstetric complication in developing countries associated with poor fetal and maternal outcome [5] [6]. One of the impasses that the obstetrician frequently meet is how to keep the maternal and neonatal morbidity to the least when given a select between difficult vaginal instrumental delivery and caesarean section at full dilatation cervix [5].

The percentage of second stage Cesarean Section is on the rise as there is a higher incidence of failure of instrumental delivery, and patients' reluctance to instrumental delivery especially forceps as cesarean section is a safer option and strict guidelines for the length of labor [6].

Emergency cesarean section and delivery of the fetus are difficult in advanced second stage of labor as fetal head is deeply impacted in the pelvis and carriage, a higher risk of complications for both the mother and the baby. The difficulty in delivering the fetal head is because of lack of space between the bony pelvis, pelvic soft tissues and the fetal head, and in advanced labour lower segment is already thin, overstretched and edematous [7].

When excessive manipulation is done to deliver the fetal head there is a high risk of injury to uterine vessels, trauma to urinary tract and extensions of lower segment. A relatively high transverse uterine incision is often necessary to avoid incision through the vagina and avoid injury of bladder uterine. These constraints often result in incisions at the level of the fetal trunk [8]. To overcome the difficulty of delivering the fetus and reducing maternal and fetal morbidity during cesarean section, different techniques have been modified like Head push, Reverse breech extraction.

One option to deliver impacted fetal head in emergency CS is the conventional head push technique (push method) using an assistant hand in the vagina to push the head up toward the uterine incision while the operator tries to pass his/her hand below the head to dislodge the head from pelvis. Alternatively a reverse breech extraction technique (pull method) is usually performed by opening the uterus soon to reach into the upper segment for a fetal leg, and by applying gentle traction on the leg until the another leg appeared. Then both legs are held together and the body of fetus could be delivered (pulled) out of the uterus completely using technique similar to that for a breech delivery [9].

The purpose of this study is to compare the complications (maternal and fetal) of reverse breech extraction (Pull) technique versus Head push technique (push) in delivering the deeply wedged fetal head during emergency caesarean section with active advanced labor.

\section{Patients and Method}

This prospective comparative study was conducted at maternity Hospital of Obstetrics and Gynecology Department, Zagazig University Hospitals from April 2011 to May 2012. Inclusion criteria were Singleton term pregnancy (according to the date of last normal menstrual period or early first trimester ultrasonography), Cephalic presentation, advanced labor with cervical dilation $\geq 7 \mathrm{cms}$ with deeply impacted fetal head in maternal pelvis. All women were diagnosed as having obstructed labor that requires an abdominal delivery by Cesarean Section. Women with multiple pregnancy, non-cephalic presentation, previous uterine scar, or gestational age $<37$ weeks were excluded. Eighty $(n=80)$ women who met our inclusion criteria were included in this study. They were divided into two groups. Group A $(n=40)$ were delivered by Reverse breech extraction and Group B ( $n=40)$ were delivered by head push method. Allocation of women to either group was made randomly based on 1:1 ratio. We started randomization by rotary. Written consent was obtained from each member before operation. In reverse breech extraction technique, a high transverse incision was set over stretched lower uterine segment where loose fold of visceral peritoneum is attached, at the level of the anterior shoulder of the fetus as the head is deeply impacted. As soon as the incision was given anterior shoulder came out spontaneously or it was gently pulled out of the uterus as space was created for the surgeon to enter his/her hand or two fingers inside the uterine cavity and examine for the anterior foot. Once the foot was grasped, traction was applied on the foot with fundal pressure to bring the foot and subsequently the whole lower limb, the other limb, trunk and head outside the cavity. In head push technique, an assistant was used to push the fetal head vaginally while the surgeon attempts to pass his/her hand below the head to dislodge the head from pelvis [10] [11]. 
The angles of the uterine incision were clamped, and any extension was noted. An extension was defined as unintended extension of uterine incision beyond normal limits. The rest of the procedure was completed by the standard method. The blood loss was estimated by measuring blood in the suction apparatus, was repeated 24 hours after operation. Maternal outcome intraoperative in the form of complications like uterine artery injury, uterine incision extension, urinary tract Injury, intrapartum hemorrhage, and Postoperative complications like postpartum hemorrhage, Postoperative blood transfusion Infected wound, hospital stay. Fetal outcome was assessed in both groups and compared to each other. The institution ethical committee approved the study protocol.

The data were processed using the Statistical Package for Social Sciences (SPSS 12). Mean and standard deviation as well as proportion were used as appropriate for describing data. Chi square test was used for qualitative variables and student-t test for quantitative variables. The 95\% confidence intervals CI and odds ratio OR were calculated as appropriate. A $p<0.05$ was considered statistically significant.

\section{Results}

Eighty pregnant women with full term pregnancy in advanced labor were included in this study. All patients had emergency Cesarean section with impacted fetal head.

Table 1 represented the demographic data of the participants of both groups. There were no statistically significant differences between them. Table 2 represented intraoperative maternal complications. There was significant difference between both groups. Extension of the uterine incision, it was significantly lower in group A 8 cases than in group Bin 20 cases with $p$ value 0.001 . No bladder injury happened in group A but there were 2 cases had that injury in group B. It was needed to intraoperative blood transfusion in 2 cases only of group A, but in group B, 10 cases needed to blood transfusion with $p$ value 0.02 . Operative time was significantly longer in group B in compare with time was spent in group A with $p$ value 0.001 . Blood loss was significantly more in group B than in group B with $p$ value 0.001 . No case of rupture uterus occurred in either group. Table 3 represented postoperative maternal complications. There were no significant differences between both groups except in fall in hemoglobin level, it was more in group B than in group A. Table 4 represented fetal outcome in both studied groups. No statistically significant differences between them.

\section{Discussion}

Cesarean sections in the second stage of labor are often associated with higher complications rate and morbidity [10]-[12]. It is still a common problem in our nation mainly in rural area to face many cases of prolonged obstructed labor when the fetal head is deeply impacted in the pelvis after unsuccessful attempts at home delivery, whether assisted or not by unskilled midwives. Performing Cesarean Section in such situation is often difficult and problematic, because the lower uterine segment may be significantly overstretched, and the standard lower segment incision might be placed too low into the vagina with possible extension into the lower part of broad ligament, profuse bleeding from uterine vessels laceration, and potential injury of the ureter [13]. Moreover, the presence of fetal head molding and caput succedaneum could likely make the disengagement of the fetal head very difficult [14].

Delivery in this circumstance could be tried by either slipping of surgeon hand deeply into the lower uterine segment between the symphysis pubis and fetal head with gentle elevation of fetal head with the fingers and palm through the incision, with accepting the probability of lower uterine segment tears. However, if the need for assistance with a hand from below is recognized before the Cesarean is taken, the legs of the lady can be placed in a supine frog-leg or modified lithotomy position. The assistant pushing the head up from the vagina (push technique) should try to flex the fetal head. If possible, three or four fingers or a cupped hand or the palm of the hand should be used to apply force widely across the presenting part to avoid the risk of fetal skull fracture [10] [15].

Another alternative is reverse breech extraction technique (pull method) performed by opening the uterus high to reach into the upper segment for a fetal leg, and by applying gentle traction on the leg until another leg appeared. Then both legs are held together and the body of fetus could be delivered in a way similar to breech delivery.

This study compared delivery of impacted fetal head by reverse breech extraction (pull) method versus pushing the fetal head up through a vagina (Push) method. 
Table 1. The demographic characteristics of studied groups.

\begin{tabular}{cccccc}
\hline \multirow{2}{*}{ variable } & \multicolumn{2}{c}{ Group A Pull group N (40) } & \multicolumn{2}{c}{ Group Push group N (40) } & $p$ value \\
\cline { 2 - 5 } & Range & Mean & Range & Mean & \\
\hline Age & $18-45$ & $23.5 \pm 4.6$ & $19-44$ & $22.7 \pm 4.7$ & 0.4 \\
Parity & $0-5$ & $2.2 \pm 1$ & $0-5$ & $2.4 \pm 1.2$ & 0.3 \\
Age & $37-41$ & $39.51 \pm 1.2$ & $37-41$ & $39.42 \pm 1.1$ & 0.6 \\
Preoperative HB & $10-12$ & $11.31 \pm 4.5$ & $10-12$ & $11.12 \pm 4.1$ & 0.8 \\
\hline
\end{tabular}

The data are presented as mean $\pm \mathrm{SD}$ or $\mathrm{n}(\%), P$ value $<0.05$ is significant.

Table 2. Intraoperative maternal complications.

\begin{tabular}{cccc}
\hline variable & Group A Pull group N (40) & Group Push group N (40) & $P$ value \\
\hline Extension of incision & $8(20 \%)$ & $20(50 \%)$ & 0.001 \\
Injury to urinary bladder & $0(0 \%)$ & $2(5 \%)$ & 0.41 \\
Intraoperative Blood transfusion & $2(5 \%)$ & $10(25 \%)$ & 0.02 \\
Operative time, min & $59.7 \pm 4.2 \mathrm{~min}$ & $75.2 \pm 6.1 \mathrm{~min}$ & 0.001 \\
Rupture of uterus & 0 & $1321 \pm 572 \mathrm{ml}$ & 0.001 \\
\hline
\end{tabular}

The data are presented as mean \pm SD or $\mathrm{n}(\%), P$ value $<0.05$ is significant.

Table 3. Postoperative maternal complications.

\begin{tabular}{|c|c|c|c|}
\hline variable & Group A Pull group N (40) & Group Push group N (40) & $P$ Value \\
\hline Postpartum hemorrhage & 2 & 5 & 0.06 \\
\hline Blood transfusion & 4 & 7 & 0.07 \\
\hline Mean fall in $\mathrm{Hb} / \mathrm{dl}$ & $1.25 \pm 0.4$ & $2.1 \pm 25$ & 0.003 \\
\hline Wound infection & 1 & 2 & 0.52 \\
\hline Mean hospital stay & $3.2 \pm 1.4$ & $3.8 \pm 1.3$ & 0.72 \\
\hline
\end{tabular}

The data are presented as mean \pm SD or $\mathrm{n}(\%), P$ value $<0.05$ is significant.

Table 4. Fetal outcome.

\begin{tabular}{cccc}
\hline variable & Group A Pull group N (40) & Group Push group N (40) & \\
\hline Apgar Score 1min & $\mathbf{1 2 ( 3 0 \% )}$ & $\mathbf{1 6}(\mathbf{4 0 \% )}$ & 0.280 \\
Apgar Score 5 min & $\mathbf{5 ( 1 2 . 5 \% )}$ & $\mathbf{9 ( 2 2 . 5 \% )}$ & $\mathbf{0 . 3 1 2}$ \\
Admission to neonatal care unit & $\mathbf{4}$ & $\mathbf{7}$ & 0.176 \\
\hline
\end{tabular}

The data are presented as mean $\pm \mathrm{SD}$ or $\mathrm{n}(\%), P$ value $<0.05$ is significant.

Our study showed that the intraoperative complications mainly extension of the uterine incision was occurred significantly lower in the "pull" compared to the "Push" method. A finding that agreed with study of Levy et al. in 2005 who found that the extension of uterine incision among the "push" method versus "pull" method was significantly higher (50\% versus $15 \%, p<0.05$ ) [15]. However, from our experience in many cases, the extension tear related to the "push" method can be at least minimized when some preventive actions are taken at the time of cesarean section. Mobilization of the bladder off the cervix deeply downwards could likely protect the bladder from possible involvement when the extension tears do occur. Also, when the surgeon's fingers can get 
beneath the presenting part, it is advisable to sustain the elevation of the fetal head upwards until it brings the lower and flexed part of the vertex into the open incision. The delivery of the head before this point may result in laceration. Similarly, using excessive force to deliver the fetal head may result in extension of the uterine incision.

Also, we found that (pull) method was associated with significantly lower amount of blood loss intraoperative, besides lesser operative time compared to (push) method. These findings are analogous to the study of Baloch et al. 2008 who discussed that reverse breech extraction can be achieved if a high transverse, or J-shaped incision is made in the lower segment [16].

It is vital for the surgeon to be prepared and experienced for using various maneuvers punctually. As the occurrence of prolonged obstructed labor in the developing nations is doubtful to be disregarded until now, training the resident doctors the simple thought of the maneuvers mandatory when met with a real situation should be addressed. In this current study, there were no significant.

No significant differences in the postoperative complications such as wound infection, hospital stay and postpartum hemorrhage was detected between both groups. This went in line with result of Kaima, et al. 2011 [17]. But, in disagreement with Fasubaa et al. 2002 who reported a higher postoperative infection rate in form of endometritis in the "push" method compared to reverse breech extraction. It seems logical that passage of the assistant's hand (who mostly is not part of the operating team) into the vagina can never be under sterile conditions, and therefore contamination of the operating field should be anticipated [18].

Our study revealed that postpartum decrease in hemoglobin level was more in second group (push) than in (pull) group and this was explained by increase the intrapartum hemorrhage among the (push) group and so increased blood loss. That result was in agree with result of Thura. 2009 and Kaima, et al. 2011.

The results neonatal outcome in our study was slightly better in the pulling method group than in pushing group but with no significant difference and this agree with result of study of Thura.

\section{Conclusions}

Cesarean section for women with prolonged and obstructed labor when the fetal head is deeply impacted in the pelvis is linked with difficulty.

Disengagement and possible risks for maternal catastrophe are tissue injury, excessive and blood loss. Delivery of the upper fetal pole first (reverse breech extraction) or pull method in such a position is a good-looking decision and harmless substitute to the pushing method to decrease such maternal complications.

\section{References}

[1] Betran, A.P., Merialdi, M., Lauer, J.A., et al. (2007) Rates of Cesarean Section: Analysis of Global, Regional and National Estimates. Paediatric and Perinatal Epidemiology, 21, 98-113.

[2] Brady, E., Hamilton, Joyce, A., Martin, M.P.H. and Stephanie, J., Ventura, M.A. (2012) National Vital Statistics System. Division of Vital Statistics. Births: Preliminary Data for 2012.

[3] Cunningham, M. (2001) Gant. Caesarean Section. William’s Obstetrics. 28th Edition, 518-519.

[4] Hallak, M. (1999) Poor Progress in Labor. High Risk Pregnancy Management Options. 2nd Edition, 1113-1114.

[5] Kafali, H. (2003) Cesarean Breech Extraction for Impacted Fetal Head in Deep Pelvis after a Prolonged Obstructed Labor: A Cesarean Technique Variation. The Internet Journal of Gynecology \& Obstetric, 2, 2.

[6] Farah, Z., Seema, H. and Tamkin, K. (2013) Delivery of the Deeply Engaged Fetal Head during Cesarean Section in Advanced Labour: A Comparative Study of Head Pushing versus Reverse Breech Extraction. Current Pediatric Research, 17, 41-43.

[7] Blickstein, I. (2004) Difficult Delivery of the Impacted Head during Cesarean Section.

[8] Levy, R., Chernomoretz, T., Appleman, Z., Levin, D., Or, Y. and Hagay, Z.J. (2005) Head Pushing versus Reverse Breech Extraction in Case of Impacted Fetal Head during Cesarean Section. The European Journal of Obstetrics \& Gynecology and Reproductive Biology, 121, 24-26. http://dx.doi.org/10.1016/j.ejogrb.2004.09.014

[9] Robert, L.B. (2012) Difficult Fetal Extraction at Cesarean Delivery: What Should You Do? Next Time You Face This Hazardous Scenario, Try Reverse Breech Extraction, 24, 1.

[10] Copra, S., Bagga, R., Keepanasseril, A., Jain, V., Kalara, J. and Suri, V. (2009) Disengagement of Deeply Engaged Fetal Head during Cesarean Section in Advanced Labor: Conventional Method versus Reverse Breech. Acta of Scandinavian Obstetrics and Gynecology, 88, 1163-1166. http://dx.doi.org/10.1080/00016340903214932 
[11] Farah, Z., Seema, H. and Tamkin, K. (2013) Delivery of the Deeply Engaged Fetal Head during Cesarean Section in Advanced Labour: A Comparative Study of Head Pushing versus Reverse Breech Extraction. Current Pediatric Research, 17, 41-43.

[12] Dolea, C. and Abouzahr, C. (2003) Global Burden of Obstructed Labour in the Year 2000. Evidence and Information for Policy, World Health Organization, Geneva.

[13] Chopra, S., Bagga, R., Keepanasseril, A., Jain, V., Kalra, J. and Suri, V. (2009) Disengagement of the Deeply Engaged Fetal Head during Cesarean Section in Advanced Labor: Conventional Method versus Reverse Breech Extraction. Acta of Scandinavian Obstetrics and Gynecology, 88, 1163-1166. http://dx.doi.org/10.1080/00016340903214932

[14] Blickstein, I. (2004) Difficult Delivery of the Impacted Fetal Head during Section: Intraoperative Disengagement Dystocia. Journal of Perinatal Medicine, 32, 465-469. http://dx.doi.org/10.1515/JPM.2004.152

[15] Levy, R., Chemomoretz, T., Appleman, Z., Levin, D., Or, Y. and Hagay, Z.J. (2005) Head Pushing versus Reverse Breech Extraction in Cases of Impacted Fetal Head during Cesarean Section. The European Journal of Obstetrics \& Gynecology and Reproductive Biology, 121, 24-26.

[16] Baloch, S., Khaskheli, M., Khushk, I.A. and Sheeba, A. (2008) Frequency of Second Stage Intervention and Its Outcome in Relation with Instrumental Vaginal Delivery versus Caesarean Section. Journal of Ayub Medical College Abbottabad, 20, 87-90.

[17] Kaima, A.F., Abdulhakim, A.E. and Abdelrahman, H.A.-H. Reverse Breech Extraction versus Head Pushing in Cesarean Section for Obstructed Labor. Saudi Medical Journal, 32, 1261-1266.

[18] Fasubaa, O.B., Ezechi, O.C., Orji, E.O., Ogunniyi, S.O., Akindele, S.T., Loto, O.M., et al. (2002) Delivery of the Impacted Head of the Fetus at Caesarean Section after Prolonged Obstructed Labor: A Randomised Comparative Study of Two Methods. Journal of Obstetrics \& Gynaecology, 22, 375-378. http://dx.doi.org/10.1080/01443610220141290 